УДК 552.513

ПЕСЧАНЫЕ ПОРОДЫ ПУР-ТАЗОВСКОЙ НЕФТЕНОСНОЙ ОБЛАСТИ: ЛИТОЛОГИЧЕСКИЕ ОСОБЕННОСТИ И ИХ ВЛИЯНИЕ НА ФИЛЬТРАЦИОННО-ЕМКОСТНЫЕ ПАРАМЕТРЫ КОЛЛЕКТОРА

1черданцева Д.А., ${ }^{1}$ Кравченко Г.Г., ${ }^{2}$ Краснощекова Л.А.

${ }^{1}$ Акционерное общество «Томский научно-исследовательский и проектный институт нефти и газа», Томск, е-mail: cherdantsevada@tomsknipi.ru;

${ }^{2}$ ФАОУ ВО «Национальный исследовательский Томский политехнический университет», Томск, e-mail: krasnl@tpu.ru

В статье рассмотрен вопрос о влиянии вещественного состава и процессов постседиментационного преобразования нижнемеловых песчаников Пур-Тазовской нефтеносной области на зависимость их пористости (Кп) от проницаемости (Кпр). На основании изучения кернового материала, петрографического анализа и расчета пористости на специализированном программном комплексе «Керн С7» установлено, что в изученных породах преимущественное развитие имеют изолированные и сообщающиеся межзерновые поры угловатой и заливообразной формы, в подчиненном количестве присутствуют внутризерновые поры, развитые вдоль плоскостей спайности и двойникования в частично растворенных зернах полевых шпатов. В участках шлифов с каолинитовым цементом фиксируется микропористость в межпакетных промежутках. Изучение пористости с использованием панорамных снимков шлифов позволило сопоставить данные литологического исследования с данными пористости песчаников по гелию. Выведена формула, численно отражающая влияние аутигенной цементации и степени уплотнения породы на ее фильтрационно-емкостные параметры. Сделаны выводы о том, что полученные поправочные коэффициенты отражают способ выполнения порового пространства различными видами цементов. В количественном выражении установлен вклад каждого литологического параметра в формирование зависимости Кп от Кпр. Поправка на содержание каолинита в поровом пространстве позволила скорректировать величину достоверности аппроксимации на графике зависимости пористость от проницаемости для песчаников Лодочного месторождения на 5\%, содержание иллита - на 4,5\%, кальцита - на $2 \%$. Поправка на соотношение среднего размера зерен к среднему размеру пор внесла корректировку еще на $1 \%$. С учётом указанных поправок, корректирующих значения общей пористости, коэффициент достоверности аппроксимации составил 0,98. Последующий анализ, проведённый авторами ещё на трёх скважинах, подтвердил значения корректирующих коэффициентов для всей площади месторождения. С точки зрения практической значимости полученные данные могут быть использованы для создания методики геологически обоснованного моделирования проницаемости на месторождении.

Ключевые слова: Красноярский край, песчаники, Ванкорская группа месторождений, проницаемость, терригенный коллектор, пористость

\title{
LITHOLOGICAL FEATURES INFLUENCE ON POROSITY AND PERMEABILITY OF OIL-BEARING SANDSTONES
}

${ }^{1}$ Cherdantseva D.A., ${ }^{1}$ Kravchenko G.G., ${ }^{2}$ Krasnoschekova L.A.

${ }^{1}$ Tomsk Oil and Gas Research and Design Institute, Tomsk, e-mail: CherdantsevaDA@tomsknipi.ru;

${ }^{2}$ National Research Tomsk Polytechnic University, Tomsk, e-mail: krasnl@tpu.ru

The paper considers the question about the material composition and diagenesis processes transform the sandstone porosity/permeability dependence. Based on the core material study, petrographic analysis and porosity calculation with a specialized program Kern C7, the authors proposed a method for lithological based prediction of the permeability in terrigenous reservoirs. According to the petrographic study, it has been established that in the sandstones of the Lodochnoe deposit, isolated and intergranular pores with an angular and bay-like shape are predominantly developed, there are sub granular pores along the cleavage and twinning planes in partially dissolved feldspar grains. In thin sections with kaolinite cement, microporosity is recorded in the inter-package spaces. The porosity study using panoramic images of thin sections made it possible to compare the lithological data study with the sandstone porosity data by helium. The derived formula numerically reflects the influence of authigenic cementation and the rock compaction degree on its filtration parameters. It is concluded that the obtained correction factors reflect the way of filling the pore space with different cement types. In quantitative terms, the contribution of each lithological parameter to the dependence Kpor on Kperm was established. The correction for the kaolinite content in the pore space made it possible to correct the coefficient R2 on the plot porosity on permeability for sandstones from the Lodochnoe deposit by $5 \%$, the illite content by $4.5 \%$, and calcite by $2 \%$. Correction for the ratio of the average grain size to the average pore size $-1 \%$. Taking into account the above-mentioned corrections, correcting the values of the total porosity, the approximation confidence value was 0.98 . Subsequent analysis carried out by the authors on three more wells confirmed the values of the correction factors for the entire field. From the point of practical significance, the obtained data can be used to create a methodology for geologically based modeling of permeability in the field.

Keywords: Krasnoyarsk Territory, sandstones, Vankor permeability, terrigenous reservoir, porosity

Преимущественное влияние структуры порового пространства на поведение относительных фазовых проницаемостей было выявлено в результате многочисленных экспериментальных исследований в области многофазной фильтрации $[1,2]$. Аспек- 
ты влияния литологических параметров на фильтрационно-емкостные и петрофизические свойства пород рассмотрены в работах таких исследователей, как R. Weibel [3], K. Bjørlykke [4], L. Liu [5] и др. Установлено, что сложная поровая структура является решающим фактором, оказывающим воздействие на особенности фильтрации флюида в пластах-коллекторах, и создает определенные сложности при разведке и разработке месторождений [6]. Однако подробное изучение строения порового пространства продуктивных песчаников с акцентом на литологию открывает возможности для построения максимально точных геологических моделей многопластовых залежей углеводородов. Для разработки методики прогнозирования проницаемости терригенных коллекторов с учетом структурно-вещественных параметров пород авторами был использован керновый материал и петрографические шлифы по Лодочному нефтегазоконденсатному месторождению. Административно объект расположен на территории Туруханского района Красноярского края и входит в состав Ванкорской группы месторождений Пур-Тазовской нефтеносной области. В орографическом отношении изучаемая территория приурочена к центральной части Нижне-Енисейской возвышенности Западно-Сибирской низменности. С тектонической точки зрения Нижне-Енисейская возвышенность является отражением в рельефе положительных линейных тектонических структур мезозойскокайнозойского платформенного чехла - Сузунского и Лодочного валов, осложняющих Большехетскую структурную террасу. В геологическом строении изучаемой территории принимают участие метаморфические образования архейско-среднепротерозойского возраста, осадочные образования палеозойского и мезозойско-кайнозойского возраста. Разрез мезозойско-кайнозойских отложений изучен по материалам глубокого бурения и представлен отложениями юрско-мелового и четвертичного возраста. Продуктивные пласты месторождения относятся к нижнехетской, малохетской, суходудинской и яковлевской свитам нижнего мела.

Целью исследования являлось определение и численная оценка влияния процессов седиментогенеза и постседиментационного преобразования пород на фильтрационно-емкостные параметры продуктивных песчаников Пур-Тазовской нефтеносной области на примере Лодочного месторождения углеводородов.

\section{Материалы и методы исследования}

Исследовались образцы песчаных пород продуктивных пластов нижнехетской и яковлевской свит. Определение фильтрационно-емкостных свойств (ФЕС) проводилось на ста пяти цилиндрических образцах диаметром 30 мм, из торцевой части которых изготавливались прокрашенные синей эпоксидной смолой шлифы.

Коэффициенты открытой пористости и газопроницаемости определялись анализатором пористости и газопроницаемости пород АР-608. Петрографический анализ проводился на поляризационном микроскопе Olympus BX-53 с дальнейшим детальным изучением размерных характеристик пустотного пространства с помощью специализированной программы «Керн С7». Полное петрографическое описание шлифов терригенных пород включало в себя: определение вещественного состава образцов с подсчетом содержания и описания основных породообразующих компонентов, цементов, пустотно-порового пространства; измерение гранулометрических параметров обломочного материала; анализ проявленных постседиментационных изменений в песчаниках.

\section{Результаты исследования и их обсуждение}

При петрографическом изучении шлифов, помимо характеристики структурновещественного состава пород, устанавливаются также особенности пустотно-порового пространства (характер пористости, форма, распределение, степень сообщаемости пор) и особенности проявления цементирующего материала в породе; фиксируется степень уплотнения обломков в породе. Авторы предприняли попытку учесть все вышеперечисленные данные в единой формуле, описывающей математическую модель песчаника, путем подбора коэффициентов для определения степени влияния тех или иных литологических параметров на фильтрационно-емкостные характеристики пород.

Представляется, что в идеальных песчаниках существует зависимость пористости от проницаемости. Однако в реальности к нарушению такой зависимости приводят: непостоянство формы зёрен и их контактов, различная степень уплотнения пород, формирование в поровом пространстве песчаника аутигенных цементов, наличие включений, текстурная неоднородность породы и т.д. В связи с тем, что количество изме- 
ряемых литологических параметров, оказывающих влияние на проницаемость, может измеряться десятками, создание единой функции, связывающей их воедино, представляется достаточно сложной задачей (по крайней мере, на данном этапе исследования). Поэтому в работе подбиралась зависимость, построенная с использованием всего лишь нескольких, наиболее весомых на основании практического опыта авторов, литологических параметров, а именно:

- содержаний пяти основных типов цементов по минеральному составу (каолинитовый, иллитовый, хлоритовый, сидеритовый и кальцитовый);

- параметров гранулометрического распределения зёрен (медианный диаметр);

- параметров распределения пор по размерам (использовался тот же подход, что и для гранулометрии).

В условно идеальной модели песчаных формирований без учета цементирующей части и при условии хорошей сортированности материала размер пор будет напрямую зависеть от размера обломков и степени их уплотнения, а проницаемость будет иметь экспоненциальную зависимость от пористости. На рис. 1 на графике зависимости медианного диаметра зерен от проницаемости породы (Кпр) (на примере образцов из скважины № 445 Лодочного месторождения) отмечается, что ряд песчаников не подчиняется экспоненциальному распределению и величина достоверности аппроксимации составляет всего 0,1041.

Для выявления причины такого распределения авторами был проанализирован ве- щественный состав образцов, выделенных оранжевым цветом. Все указанные образцы представлены известковистыми и известковыми песчаниками с содержанием кальцита выше $12 \%$. Предположим, что для учета влияния карбонатности на ФЕС возможно подобрать коэффициент, отражающий содержание карбонатов в песчанике, и по аналогии это возможно сделать и для других видов аутигенного цемента.

Чтобы подтвердить выдвинутое предположение, обратимся к графикам зависимости проницаемости песчаника от содержания цементов разного состава (рис. 2). На приведённых графиках видно, что существующие в породе зависимости сложно описать простыми функциями. Это указывает на необходимость создания комплексного коэффициента, способного учитывать сразу ряд параметров:

1) состав цементирующего материала и его количество;

2) размер обломков;

3) степень уплотнения или вторичного разуплотнения породы;

4) размер и форму пор, степень их сообщаемости и однородность распределения;

5) однородность состава породы (текстурно-структурные характеристики).

Для анализа зависимостей вещественный состав песчаников был сопоставлен с данными гранулометрического анализа, а также данными по пористости и проницаемости образцов по гелию. Решение поставленной задачи сводилось к подбору поправочных коэффициентов, таким образом, чтобы максимально приблизить вид графика $\mathrm{K}_{\text {п }}\left(\mathrm{K}_{\text {пр }}\right)$ к экспоненциальному виду.

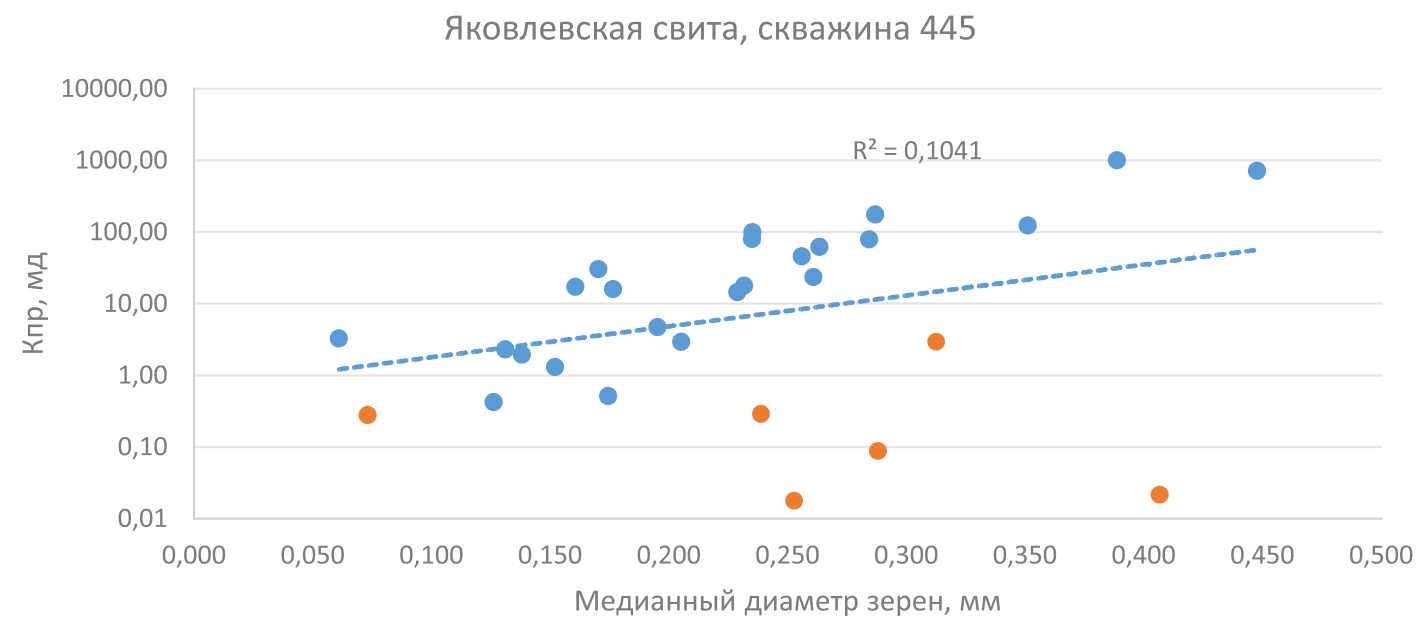

Рис. 1. График зависимости проницаемости песчаника (Кпр) от медианного диаметра слагающих его зерен. Образиы, содержащие карбонатный иеемент выше $12 \%$, выделены оранжевым цุветом 

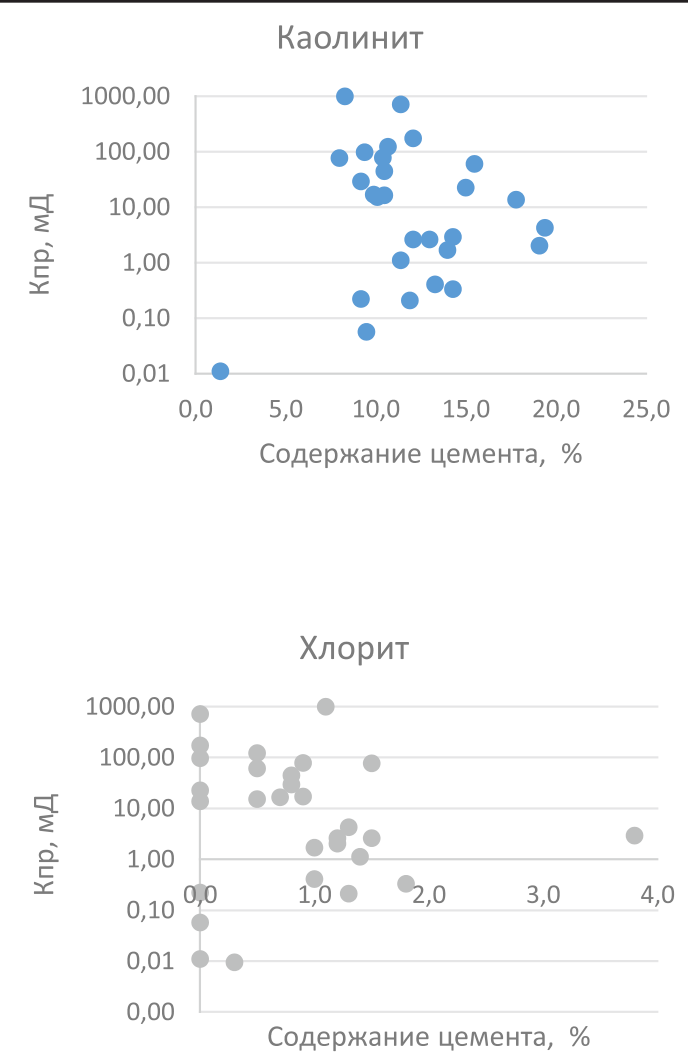
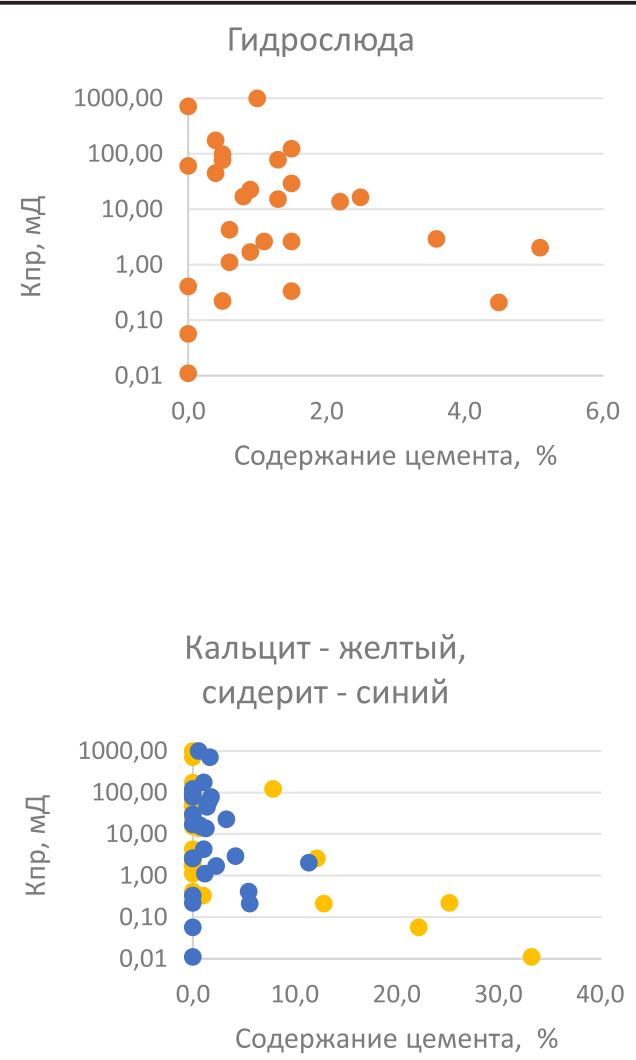

Рис. 2. Графики зависимостей проницаемости от содержания цеементирующего материала

Содержание цементирующего материала в песчаниках продуктивных пластов

\begin{tabular}{|l|c|c|c|c|c|c|}
\hline \multicolumn{1}{|c|}{$\begin{array}{c}\text { Литологические } \\
\text { коэффициенты }\end{array}$} & $\begin{array}{c}\mathrm{A} \\
\text { каолинит }\end{array}$ & $\begin{array}{c}\mathrm{B} \\
\text { иллит }\end{array}$ & $\begin{array}{c}\mathrm{C} \\
\text { хлорит }\end{array}$ & $\begin{array}{c}\mathrm{D} \\
\text { кальцит }\end{array}$ & $\begin{array}{c}\mathrm{E} \\
\text { сидерит }\end{array}$ & $\mathrm{M}$ \\
\hline Верхнеяковлевская & $-0,60$ & $-2,30$ & $-0,20$ & $+0,23$ & $-0,10$ & 0 \\
\hline Нижнеяковлевская & $-0,35$ & $-0,10$ & $-0,30$ & $+0,10$ & $-0,10$ & 0 \\
\hline Нижнехетская Нх-I & $-1,20$ & 0 & $-0,15$ & 0 & 0 & 25 \\
\hline Нижнехетская Нх-III-IV & $-0,60$ & $-0,15$ & $-0,75$ & $+0,03$ & $-0,30$ & 4 \\
\hline
\end{tabular}

Полученные таким способом значения пористости были названы $\mathrm{K}_{\text {п }}$ (лит) (пористость с поправкой на литологию), а для оценки степени приближения зависимости к идеальному (экспоненциальному) виду использовался показатель достоверности аппроксимации R2, рассчитываемый автоматически в MS Excel. Для расчёта пористости с поправкой на литологию использовалась следующая формула:

$$
\begin{aligned}
& \text { Кп(лит) }=\text { Кп + } \mathbf{A}^{*} \mathbf{V} \text { каол }+\mathbf{B}^{*} \mathbf{V} и л+ \\
& +\mathbf{C}^{*} \mathbf{V} \mathbf{x л}+\mathbf{D}^{*} \mathbf{V} \text { кал }+\mathbf{E}^{*} \mathbf{V} \text { сид }+\mathbf{M},
\end{aligned}
$$

где $\mathrm{K}_{\text {п }}$ (лит) - пористость с поправкой на литологию;

$\mathrm{K}_{\text {п }}$ - пористость по гелию (\%);

$\mathrm{V}^{\mathrm{II}}$ - содержание соответствующих минералогических типов цемента;
A, B, C, D, E- поправочные коэффициенты для содержаний каолинита, иллита, хлорита, кальцита и сидерита соответственно;

M - коэффициент, отражающий соотношение среднего размера пор к среднему размеру зерен (поправка на степень уплотнения); содержание цементов считалось в \% от площади шлифа. Пример содержания цемента в изучаемых породах представлен в таблице.

Физический смысл поправочных литологических коэффициентов состоит в определении объёма порового пространства, который соответствующие типы цементов исключают из процессов фильтрации. Учет влияния литологии на ФЕС путем введения поправочных коэффициентов позволил численно оценить степень влияния структурновещественных параметров породы на зависимость ее пористости от проницаемости. 
На рис. 3 и 4 приведено сравнение графиков с данными образцов до введения поправочных коэффициентов и после. В результате исследования установлено, что в песчаниках верхнеяковлевской подсвиты, наибольшее влияние на ФЕС оказали каолинит и гидрослюда (иллит) (рис. 3, А). Это вполне закономерно, поскольку для изученных пород характерна активная каолинизация, связанная с процессами растворения зерен полевых шпатов. Иллит с литологической точки зрения связан с процессами образования гидрослюдистых минералов в результате гидратации биотита, которым наиболее сильно обогащены неоднородные по своей текстуре разности изученных верхнеяковлевских песчаников. Формула для расчета пористости с поправкой на литологию в песчаных породах верхнеяковлевской подсвиты имеет вид

$$
\begin{array}{r}
\text { Кп(лит })=\text { Кп }-\mathbf{0 , 6 0} \text { ККаол }-\mathbf{2 , 3 0 * И л ~ - ~} \\
-0,20 * \text { Хл }+0,23 * \text { Кал }-0,10 * \text { Сид }+0 * \text { М. }
\end{array}
$$

Здесь и далее: Кп (лит) - пористость с поправкой на литологию, Кп - пористость по гелию в \%; содержание цементов в \% от площади шлифа, Каол - каолинит, Ил иллит (гидрослюда), Хл - хлорит, Кал кальцит, Сид - сидерит, М - медианный диаметр зерен по данным гранулометрии, мм.

В песчаных породах нижнеяковлевской свиты наибольшее влияние на ФЕС оказали каолинит и хлорит (рис. 3, Б). Каолинизация здесь также связана с активным растворением полевых шпатов, а хлоритизация - с наличием прослоев, обогащенных чешуйками хлоритизированного биотита. С учетом петрографического изучения пород в шлифах, для песчаных пород нижнеяковлевской подсвиты формула имеет вид

$$
\begin{gathered}
\text { Кп(лит) }=\text { Кп - 0,35*Каол }-0,10 * \text { Ил - } \\
-\mathbf{0 , 3 0 * Х л ~}+0,10 * \text { Кал }-0,10 * \text { Сид + } 0 * \text { М. (3) }
\end{gathered}
$$

Исходя из того, какую крупную поправку в данные вносит медианный диаметр зерен (рис. 4, А), в песчаных породах нижнехетской свиты наибольшее влияние на зависимость Кпр от Кп оказала размерность обломков и степень их сортированности. Связано это, прежде всего, с фациальными условиями. Песчаники пласта Нx-I, сформированные в условиях гребней вдольбереговых валов, отличаются наилучшей степенью сортированности и крупным размером зерен, на рис. 4, А, они отмечены красным. Наибольшую поправку из цементов внесли каолинит и хлорит, в то время как карбонаты и иллит (гидрослюда) не оказали заметного влияния.

$$
\begin{aligned}
& \text { Кп(лит })=\text { Кп }-\mathbf{1 , 2 0 * К а о л ~}-0 * \text { Ил - } \\
& -0,15 * \text { Хл }+0 * \text { Кал }-0 * \text { Сид }+25^{*} \mathrm{M}
\end{aligned}
$$

Из цементов максимальное воздействие на изменение ФЕС в песчаниках пласта Hx-III-IV нижнехетской свиты внесли каолинит, хлорит и сидерит, чуть менее заметное - иллит (гидрослюда) и кальцит.

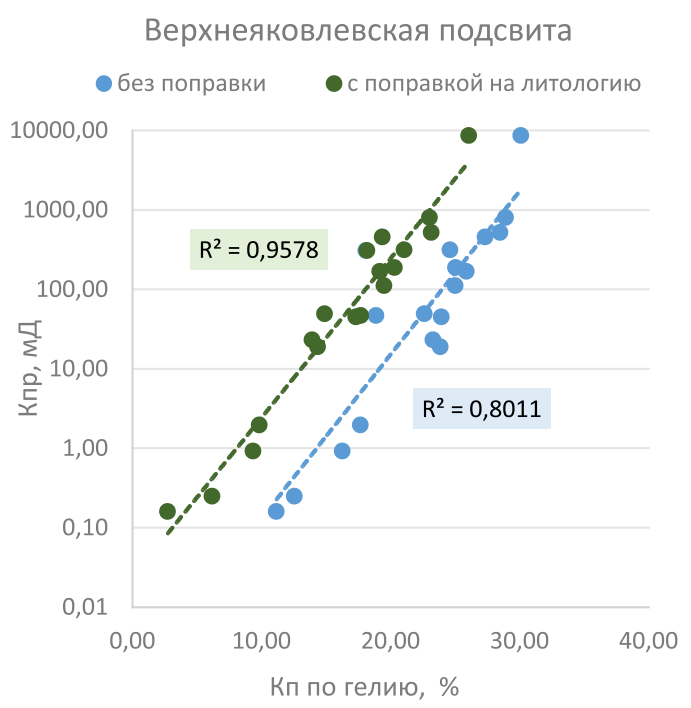

$A$

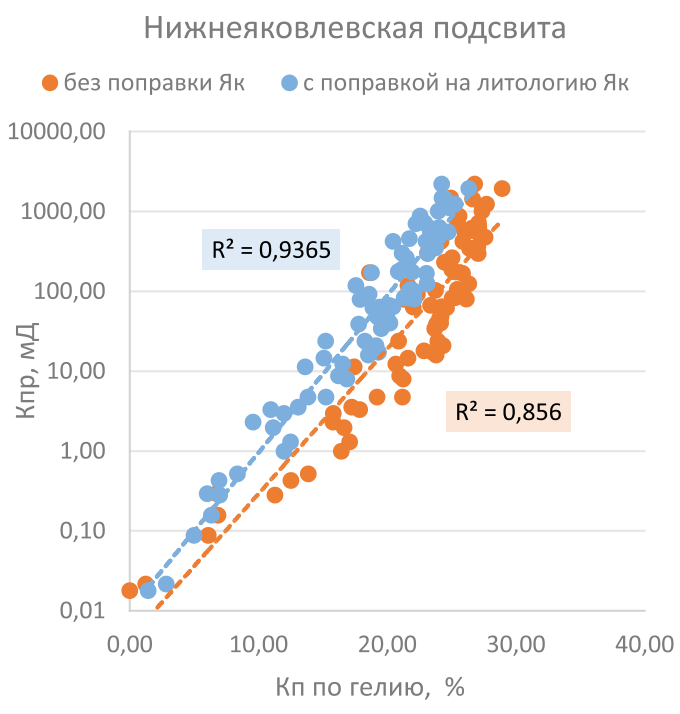

Б

Рис. 3. Графики зависимости пористости от проницаемости для образцов из отложений яковлевской свиты без учёта поправки на литологию и с учётом поправки 


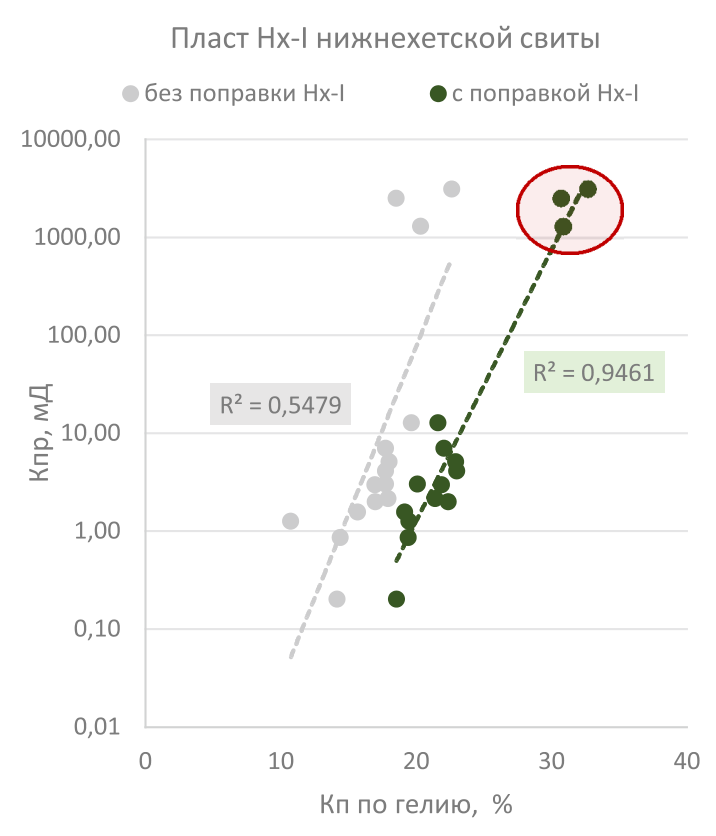

$A$

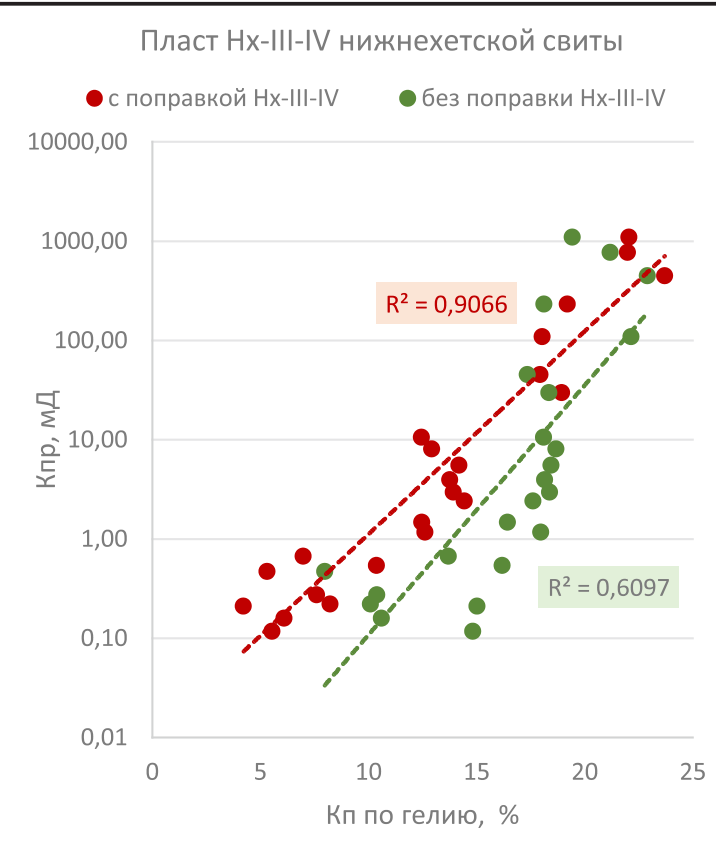

Б

Рис. 4. Графики зависимости проницаемости от пористости для образцов из пластов Нх-I (A) и Нx-III-IV (Б) нижнехетской свиты без учёта поправки на литологию и с её учётом

Сидерит в изученных образцах отмечен в тонких сильно сидеритизированных глинистых прослоях со следами биотурбации осадка. Пелитоморфный сидерит активно развивался в песчаниках, обогащенных глинистым материалом, первым из карбонатов оседал в породе и активно формировал стяжения и микроконкреции, которые впоследствии привели к снижению проницаемости пород.

В песчаных породах пласта Нx-III-IV нижнехетской свиты незначительное положительное влияние на зависимость Кп от Кпр оказали невысокие содержания (до $10 \%$ ) кальцита - выступающие маркером вторичного растворения карбонатов. Исходя из значений медианного диаметра зерен существует разграничение образцов, связанное с фациальными условиями формирования песчаников. Наибольшую поправку из цементов внесли каолинит и хлорит, чуть менее заметную - сидерит. Таким образом, для песчаных пород пласта Нx-IIIIV нижнехетской свиты были полученные следующие закономерности (рис. 4, Б):

$$
\begin{array}{r}
\text { Кп(лит })=\text { Кп }-\mathbf{0 , 6 0} * \text { Каол }-0,15 * \text { Ил }- \\
-\mathbf{0 , 7 5 * Х л ~}+0,03 * \text { Кал }-\mathbf{0 , 3 0 * С и д ~}+\mathbf{4}^{*} \text { М. }
\end{array}
$$

О влиянии размерности зерен можно судить, если сравнить графики распределения гранулометрической размерности для образцов с низкой и высокой проницаемостью представленных на рис. 5. Видно, что распределение, характерное для хорошо сортированных крупно-среднезернистых песчаников гребней вдольбереговых песчаных баров из пласта Нx-I (рис. 5, А) сильно отличается от распределения в плохо сортированных тонко-мелкозернистых песчаниках межбаровых ложбин нижнехетской свиты (рис. 5, Б).

\section{Заключение}

Bсе типы цементов, за исключением невысоких содержаний (до 10\%) фрагментов вторично растворенного кальцита, ожидаемо уменьшают пористость. На данном этапе исследования можно полагать, что цементы либо содержат изолированные микропоры, не участвующие в фильтрации, либо имеют плёночный тип распределения и могут перекрывать сообщение между относительно крупными порами. Первый тип влияния, как показывает петрографическое изучение цементов под микроскопом, типичен для каолинита, второй - для иллита и хлорита. Иллит и хлорит, благодаря плёночному характеру своего распределения, обычно не оказывают существенного влияния на проницаемость, однако в некоторых случаях могут перекрывать сообщение между порами, исключая их из процессов фильтрации. 


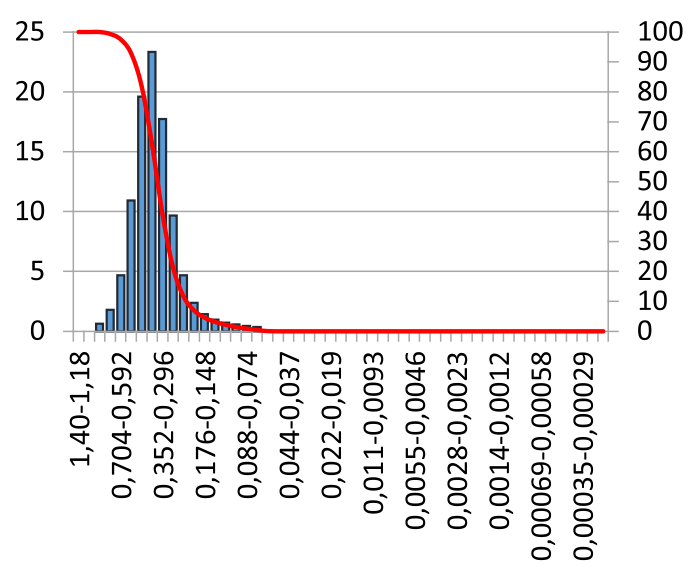

A) Kn, $\%-21,88 \mathrm{Knp}$, мД-2481,89
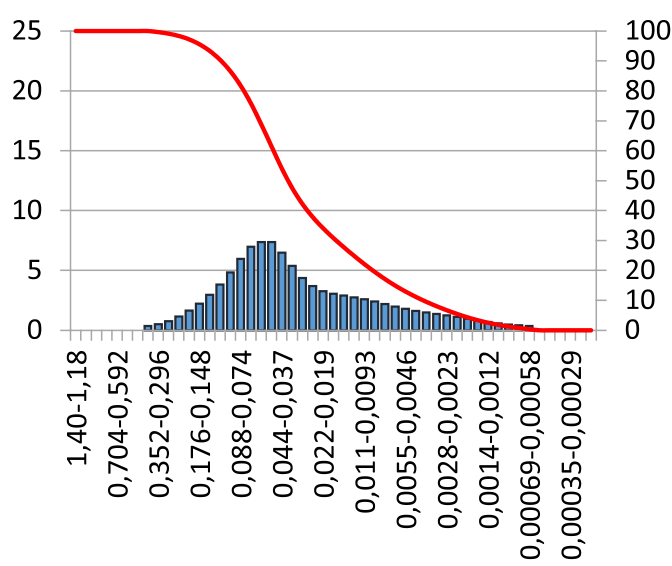

Б) Кn, $\%-20,87 \mathrm{Knp}$, мД-12,62

Рис. 5. Графики распределения гранулометрических фракций обр. № 8546-18 из скв. № 112 (А) и обр. № 9816-18 из скв. № 112 (Б)

Вероятно, в случае перекрытия иллитом и хлоритом щелевидных пор объём перекрытых межзерновых пор может превышать содержание соответствующего цемента в породе, на что указывают превышающие 1 значения поправочных коэффициентов, наблюдающиеся в некоторых случаях (Каол Hх-I, Иллит - ВЯк). Аналогичный механизм влияния на проницаемость имеет, по-видимому, и сидерит.

Интересным представляется факт улучшения проницаемости от содержания кальцита, в то время как хорошо известно, что его наличие в породе может только снижать пористость и, соответственно, проницаемость [7, 8]. Данное обстоятельство можно объяснить наличием во многих изученных песчаниках включений кальцита, несущих на себе признаки растворения. Как правило, такой кальцит находится в наиболее тупиковых частях пор или внутри зёрен. Очевидно, что осаждение кальцита, начинающееся из-за изменения рН среды, будет охватывать поры по мере ухудшения их связности. Обратный процесс растворения кальцита будет идти в противоположном направлении, т.е. начинаться в наиболее крупных из оставшихся пор и заканчиваться в наиболее мелких, включая тупиковые и внутризерновые. В связи с вышесказанным обнаружение в песчаниках кальцита в упомянутых местах авторы интерпретируют как результат растворения зон карбонатизации. Существование таких зон - не редкость в нефтяных залежах, они могут образовываться в разных частях залежей по мере миграции ВНК, в том числе с наложением друг на друга и при этом многократно подвергаться растворению за счет изменения $\mathrm{pH}$ фильтрующихся через породу флюидов. Образование кальцита в зонах карбонатизации после того, как он занял всё свободное пространство, продолжается за счёт растворения обломочных зёрен, прежде всего кварца и полевого шпата. В случае последующее полного растворения такого кальцита в песчанике возникнет дополнительная пористость, которая может существенно превышать первичную (седиментационную). Реликты кальцита в этом случае будут иметь положительную корреляционную связь с пористостью и проницаемостью.

\section{Список литературы / References}

1. Актуальные вопросы петрофизики сложнопостроенных коллекторов / Под. ред. докт. геол.-минерал. наук И.Г. Шнурмана. Краснодар: Просвещение-Юг, 2010. 306 с.

Topical issues of complex reservoirs petrophysics / Pod. red. dokt. geol.-mineral. nauk I.G. Shnurmana. Krasnodar: Prosveshcheniye-Yug, 2010. 306 p. (in Russian).

2. Cherdantseva D.A., Kravchenko G.G. and Krasnoshchekova L.A. The Pore Structure and it's Effect on OilBearing Sandstones Petrophysical Characteristics in the Lodochnoe Deposit. Conference Proceedings, Geomodel. 2020. Vol. 2020. P. 1-5. DOI: 10.3997/2214-4609.202050017.

3. Weibel R., Nielsen M.T., Therkelsen J., Jakobsen F.C., Bjerager M., Mørk F., Mathiesen A., Hovikoski J., Pedersen S.S., Johannessen P.N., Dybkjær K. Illite distribution and morphology explaining basinal variations in reservoir properties of Upper Jurassic sandstones, Danish North Sea. Marine and Petroleum Geology. 2020. № 116. P. 104290. DOI: 10.1016/j.marpetgeo.2020.104290.

4. Bjørlykke K. Relationships between depositional environments, burial history and rock properties. Some principal aspects of diagenetic process in sedimentary basins. 
Sedimentory Geology. 2014. № 301. P. 1-14. DOI: 10.1016/j. sedgeo.2013.12.002.

5. Liu L., Li Y., Dong H., Sun Z. Diagenesis and reservoir quality of Paleocene tight sandstones, Lishui Sag, East China Sea Shelf Basin. Journal of Petroleum Science and Engineering. 2020. P. 107615. DOI: 10.1016/j.petrol.2020.107615.

6. Ren D., Yang F., Li R., Zhou D., Lui D. and Li Y. Insight into the Pore Structures and Its Impacts on Movable Fluid in Tight Sandstones. Geofluids. Special Issue. 2020. P. 1-11. DOI: $10.1155 / 2020 / 8820023$.
7. Hong D., Cao J., Wu T., Dang S., Hu W., Yao S. Authigenic clay minerals and calcite dissolution influence reservoir quality in tight sandstones: Insights from the central Junggar Basin, NW China. Energy Geoscience. 2020. № 1. P. 8-19. DOI: 10.1016/j.engeos.2020.03.001.

8. Nyman S.L., Gani R.M., Bhattacharya J.P., Lee K. Origin and distribution of calcite concretions in Cretaceous Wall Creek Member, Wyoming: Reservoir-quality implication for shallow-marine deltaic strata. Cretaceous Research 2014. № 48. P. 139-152. DOI: 10.1016/j.cretres.2013.12.009. 